\title{
Norma categorial para el español de Bogotá, Colombia
}

\author{
Category norm for the Spanish spoken in Bogota, \\ Colombia
}

\author{
Albeiro Miguel Ángel Ramírez Sarmiento1 \\ Néstor Alejandro Pardo García 2
}

\section{Resumen}

En este trabajo presentamos los resultados de un estudio elaborado en Bogotá con 210 estudiantes universitarios de 5 instituciones con diferentes características sociodemográficas, con el fin de establecer las normas categoriales léxicas. Se utilizaron las 56 categorías léxicosemánticas usadas en el clásico estudio de Battig y Motague (1969) y se recogieron más de 7800 palabras que fueron organizadas por rango y moda.

En la revisión bibliográfica realizada no se encontraron trabajos de esta naturaleza para el español colombiano (o latinoamericano), y se espera que sus resultados sean usados en protocolos para el campo de la terapia del lenguaje y los estudios psicolingüísticos. Los datos recogidos fueron comparados con uno de los estudios de norma categorial realizados para el español ibérico.

\section{Palabras clave}

Norma categorial, psicolingüística, categoría léxica, español de Bogotá.

\section{Abstract}

In this article, we present the results of a study carried out in Bogotá, Colombia with 210 university students from five different universities pertaining to diverse socio-demographic groups. The objective of the study was to establish the lexical category norms. 56 lexical-semantic categories used by Battig and Montague (1969) in their classic study were employed. More than 7800 words were collected and organized by range and mode. There are no other studies on this subject for Colombian or Latin American Spanish. We hope that the results presented here will be used both in psycholinguistic and language therapy studies. The collected data were compared to one of the category norm studies made for European Spanish.

Key words

Category norm, psycholinguistics, lexical category, Bogotá Spanish.

Artículo recibido el 23 de Febrero de 2010 y aprobado el 30 de Agosto de 2010.

1 Magíster en Lingüística, Universidad Nacional de Colombia. Profesor, Institución Universitaria Colombo Americana. angelram@yahoo.com.

2 M.A. en Lingüística. Profesor Asistente, Universidad Nacional de Colombia. napardog@unal.edu.co. 


\section{Introducción}

Desde la década de los 60 los resultados de los estudios de tipicalidad léxica han sido usados en diversas tareas, que van desde trabajos psicológicos-memoria, disponibilidad léxica, etc. - pasando por protocolos de terapia del lenguaje, hasta llegar a investigaciones de corte más lingüístico. Los primeros trabajos (Battig y Montague, 1969) fueron realizados en inglés norteamericano, después, se han realizado diversas adaptaciones e interpretaciones en lenguas tipológicamente diferentes.

Así, encontramos trabajos sobre tipicalidad en francés (Dubois y Poitou, 2002), holandés (Ruts, et al, 2004), alemán (Dubois y Poitou, 2002) y español ibérico (Goikoetxea, 2000, Pascual y Musitu, 1980). Además, existen trabajos comparados que establecen paralelos en aspectos específicos, como el de Yoon (2004) que analiza la variabilidad léxica en distintos grupos etáreos en el chino y el inglés americano.

Las normas categoriales son compilaciones de las respuestas más comunes de un sujeto hablante de una lengua determinada cuando se le pide un ejemplar de alguna categoría semántica (Ejemplo: Un color: azul). El objetivo de estos inventarios es proporcionar datos que puedan ser utilizados en procedimientos de reconocimiento semántico, en los cuales se utilicen las palabras de la compilación para evocar rasgos determinados de su significado.

Por ejemplo, si se le pregunta a una persona por la categoría a la que pertenece la palabra paloma, lo más probable es que asocie esta palabra al grupo de las aves. De otro lado, un ave menos prototípica como la gallina podría ser clasificada más fácilmente dentro del grupo de los animales que dentro de aquel de las aves.

Hasta el momento no se han realizado investigaciones de esta índole para el español colombiano, solamente existe un estudio sobre la disponibilidad léxica en estudiantes bogotanos (Mateus y Santiago 2006); sin embargo, esta investigación no toca el fenómeno de la prototipicalidad. De hecho, no se encontraron estudios de normas categoriales léxicas para las variedades del español hablado en Latinoamérica. Este trabajo es el primer estudio sistemático de prototipicalidad léxica para el español de Colombia.

\section{Método \\ Participantes}

Se escogieron 210 alumnos de las carreras de lenguas extranjeras de 5 universidades de Bogotá; estudiantes de la misma carrera para evitar que el área de conocimiento específico se convierta en una variable, tal como se ha hecho en estudios anteriores. A continuación se presentan las universidades seleccionadas, el número de participantes de cada una y el porcentaje al cual equivale este número con respecto al total de la muestra: Universidad Nacional de Colombia (35) (16.7\%), Pontificia Universidad Javeriana (77) (36.7\%), Universidad de la Salle (42) (20\%), Institución Universitaria Colombo Americana (50) (23.8\%) y Universidad de los Andes (6) (2.8\%).

Estas universidades se seleccionaron porque sus alumnos pertenecen a grupos socioeconómicos muy diversos. 83 participantes fueron hombres (39.5\%) y 127 fueron mujeres (60.5\%). Los sujetos se encontraban en el rango de 16 a 44 años de edad; la edad promedio fue de 21.74 ( \pm 4.23 ). Se incluyeron participantes de diferentes estratos socioeconómicos de la ciudad: estrato 1 (7) (3.3\%), estrato 2 (50) (23.8\%), estrato 3 (83) (39.5\%), estrato 4 (53) (25.2\%), estrato $5(10)(4.8 \%)$, estrato $6(7)(3.3 \%)$.

\section{Procedimiento}

Esta investigación se llevó a cabo con el mismo procedimiento usado por Battig y Montague (1969), utilizando las mismas categorías del citado estudio para que los resultados puedan compararse con ésta y otras investigaciones de la misma naturaleza.

Los sujetos se encontraban sentados en un salón de clase y a cada uno de ellos se le proporcionó un cuadernillo de 80 hojas y un esfero. Inicialmente, se le pidió a los sujetos que lo abrieran y escribieran sus datos personales: nombre, edad, sexo, estrato socioeconómico ${ }^{3} \mathrm{y}$ universidad, a continuación, el investigador procedió a dar las instrucciones.

En primer lugar, el investigador decía el nombre de una categoría diferente de las 56 estudiadas. Los

3 En Colombia, los habitantes saben perfectamente a qué estrato socioeconómico pertenecen, pues éste afecta las tarifas de los servicios públicos y el acceso o no a ciertos beneficios estatales. Las viviendas están estratificadas del uno al seis, siendo el seis el más alto. 
sujetos comenzaban a escribir ejemplos de la categoría mientras que el investigador revisaba de manera individual las respuestas dadas por los participantes con el fin de verificar la comprensión correcta de las instrucciones por parte de los mismos.

Se les informó que solamente se aceptaban palabras en español que no fueran abreviaturas (dado que los sujetos estudiaban lenguas modernas), pero que sí se aceptaban siglas y marcas comerciales. Las categorías siempre fueron presentadas en el mismo orden, el cual ha sido usado en otros estudios, lo que evita que las respuestas varíen de acuerdo a la posición dada a la categoría en las diferentes fases de recolección de datos.

En segundo lugar, el investigador debía decir el nombre de una categoría específica, por ejemplo "frutas", desde el momento en el que este evento ocurría, los sujetos contaban con 30 segundos para escribir el mayor número posible de ejemplos de la categoría específica. Al término de los 30 segundos el investigador pedía que los sujetos dejaran de escribir y pasaran la hoja; inmediatamente después, decía el nombre de la categoría siguiente. Este proceso se repitió 56 veces, una vez para cada categoría. Al finalizar la lista de categorías, los sujetos debían entregar los cuadernillos para su posterior análisis.

\section{Resultados}

Todas las respuestas legibles dadas por los sujetos en cada categoría fueron ordenadas y sistematizadas para su posterior análisis estadístico. Los datos obtenidos de los estratos socioeconómicos 1 al 3 fueron analizados por separado de aquellos de los estratos 4 al 6, con el fin de realizar una correlación entre la variable clase social y las respuestas obtenidas.

A continuación se presentará la tabla de información general, que resume los datos obtenidos en cada categoría; tiene seis columnas, en la primera está la categoría que se elicita; la segunda y tercera columnas ofrecen el número total de palabras diferentes escritas por los sujetos, clasificadas según el grupo socioeconómico; en la cuarta columna se presenta el número de palabras diferentes escritas por todos los sujetos para la categoría en cuestión.

En la quinta columna se puede observar el promedio de palabras escritas para esta categoría específica; y, finalmente, en la sexta columna se aprecia la correlación de Pearson realizada entre los rangos, es decir, la ubicación promedio de cada palabra en la lista que cada sujeto escribió para cada categoría (por ejemplo, banano en la posición 1, manzana en la posición 2, etc.). Estos rangos fueron calculados para cada palabra, por separado, en los estratos socioeconómicos bajos (1-3) y los estratos socioeconómicos altos (4-6).

El objetivo de utilizar en la investigación la correlación de Pearson, es observar si los rangos de aparición de las palabras en cada categoría son similares en ambos grupos socioeconómicos; es decir, si según la palabra los rangos ascienden y descienden de igual manera en ambos grupos. Cuanto más se acerca el valor de la correlación de Pearson a 1, más estrecha es la relación existente entre los datos obtenidos en ambos grupos (véase figura 1).

Figura 1. Explicación de los componentes de la tabla de resultados de variable socioeconómica

\begin{tabular}{|c|c|c|c|c|c|}
\hline Categoría & $\begin{array}{c}\text { Número de } \\
\text { respuestas } \\
\text { estratos } \\
13\end{array}$ & $\begin{array}{l}\text { Número de } \\
\text { respuestas } \\
\text { estratos } \\
4-6\end{array}$ & $\begin{array}{l}\text { Número total } \\
\text { de respuestas }\end{array}$ & $\begin{array}{l}\text { Promedio de } \\
\text { respuestas por } \\
\text { categoría }\end{array}$ & $\begin{array}{c}\text { Correlación de } \\
\text { Pearson }\end{array}$ \\
\hline Una piedra preciosa & & & & 19) & \\
\hline $\begin{array}{c}\text { Nombre de la categoría } \\
\text { en cuestión }\end{array}$ & $\begin{array}{l}\text { Número de palabras } \\
\text { diferentes escritas } \\
\text { por los sujetos de } \\
\text { los estratos } 1,2 \text { y } 3 \\
\text { para la categoría en } \\
\text { cuestión. }\end{array}$ & $\begin{array}{l}\text { Número de palabras } \\
\text { diferentes escritas } \\
\text { por los sujetos de } \\
\text { los estratos } 4,5 \text { y } 6 \\
\text { para la categoría en } \\
\text { cuestión. }\end{array}$ & $\begin{array}{l}\text { Número de pala- } \\
\text { bras diferentes } \\
\text { escritas por todos } \\
\text { los sujetos para } \\
\text { la categoría en } \\
\text { cuestión. }\end{array}$ & $\begin{array}{l}\text { Promedio aritméti- } \\
\text { co de la cantidad } \\
\text { de palabras que } \\
\text { cada sujeto escri- } \\
\text { bió para la presen- } \\
\text { te categoría. }\end{array}$ & $\begin{array}{l}\text { Correlación esta- } \\
\text { blecida entre los } \\
\text { rangos dados para } \\
\text { cada palabra según } \\
\text { la clase social. }\end{array}$ \\
\hline
\end{tabular}


Figura 2. Resultados de la comparación de la variable socioeconómica

\begin{tabular}{|c|c|c|c|c|c|c|}
\hline & Categoría & $\begin{array}{c}\text { Número de } \\
\text { respuestas } \\
\text { estratos }\end{array}$ & $\begin{array}{c}\text { Número de } \\
\text { respuestas } \\
\text { estratos }\end{array}$ & $\begin{array}{l}\text { Número total } \\
\text { de respuestas }\end{array}$ & $\begin{array}{l}\text { Promedio de } \\
\text { respuestas por }\end{array}$ & $\begin{array}{l}\text { Correlación } \\
\text { de Pearson }\end{array}$ \\
\hline 1 & Una piedra preciosa & 38 & 30 & 46 & 4,19 & 0,988 \\
\hline 2 & Una unidad de tiempo & 32 & 26 & 37 & 5,50 & 0,989 \\
\hline 3 & Una relación de parentesco & 65 & 41 & 74 & 7,19 & 0,992 \\
\hline 4 & Una unidad de distancia & 36 & 21 & 40 & 4,65 & 0,983 \\
\hline 5 & Un metal & 52 & 23 & 55 & 3,86 & 0,972 \\
\hline 6 & Un material para leer & 97 & 68 & 112 & 5,15 & 0,978 \\
\hline 7 & Un grado militar & 41 & 34 & 46 & 5,36 & 0,976 \\
\hline 8 & Un animal cuadrúpedo & 72 & 51 & 73 & 7,74 & 0,981 \\
\hline 9 & Un tipo de tela & 58 & 40 & 70 & 4,63 & 0,958 \\
\hline 10 & Un color & 39 & 30 & 42 & 9,46 & 0,993 \\
\hline 11 & Un utensilio de cocina & 78 & 65 & 93 & 7,12 & 0,979 \\
\hline 12 & Un edificio para servicios religiosos & 72 & 34 & 84 & 3,09 & 0,992 \\
\hline 13 & Una categoría gramatical & 88 & 49 & 100 & 2,78 & 0,964 \\
\hline 14 & Un mueble & 61 & 48 & 71 & 5,76 & 0,972 \\
\hline 15 & Una parte del cuerpo humano & 90 & 66 & 78 & 10,31 & 0,986 \\
\hline 16 & Una fruta & 51 & 47 & 57 & 9,53 & 0,966 \\
\hline 17 & Un arma & 87 & 59 & 104 & 5,46 & 0,960 \\
\hline 18 & Un cargo de elección popular & 42 & 24 & 47 & 4,79 & 0,996 \\
\hline 19 & Un tipo de vivienda & 66 & 57 & 86 & 4,69 & 0,984 \\
\hline 20 & Una bebida alcohólica & 51 & 38 & 57 & 6,09 & 0,990 \\
\hline 21 & Un país & 109 & 86 & 122 & 9,02 & 0,963 \\
\hline 22 & Un crimen & 83 & 71 & 111 & 4,13 & 0,983 \\
\hline 23 & Una herramienta de carpintería & 76 & 61 & 94 & 5,53 & 0,972 \\
\hline 24 & Un miembro del clero & 44 & 44 & 63 & 3,92 & 0,986 \\
\hline 25 & Un condimento & 58 & 47 & 68 & 5,09 & 0,889 \\
\hline 26 & Un tipo de combustible & 48 & 34 & 56 & 3,99 & 0,968 \\
\hline 27 & Una ocupación o profesión & 154 & 108 & 178 & 6,97 & 0,950 \\
\hline 28 & Un accidente geográfico & 83 & 73 & 103 & 3,68 & 0,934 \\
\hline 29 & Un deporte & 70 & 64 & 84 & 6,51 & 0,959 \\
\hline 30 & Un fenómeno climático & 64 & 55 & 74 & 4,15 & 0,942 \\
\hline 31 & Una prenda de vestir & 66 & 54 & 73 & 8,50 & 0,983 \\
\hline 32 & Una parte de un edificio & 85 & 51 & 92 & 5,59 & 0,914 \\
\hline 33 & Un elemento químico & 100 & 71 & 110 & 6,03 & 0,963 \\
\hline 34 & Un instrumento musical & 71 & 55 & 78 & 8,03 & 0,986 \\
\hline 35 & Una moneda & 52 & 34 & 57 & 5,22 & 0,981 \\
\hline 36 & Un tipo de música & 94 & 74 & 109 & 7,18 & 0,966 \\
\hline 37 & Un ave & 80 & 63 & 88 & 6,22 & 0,928 \\
\hline 38 & Una bebida no alcohólica & 63 & 52 & 79 & 5,59 & 0,981 \\
\hline 39 & Un vehículo & 114 & 77 & 125 & 6,16 & 0,974 \\
\hline
\end{tabular}




\begin{tabular}{|l|l|c|c|c|c|c|}
\hline 40 & Una ciencia & 94 & 55 & 108 & 4,77 & 0,941 \\
\hline 41 & Un juguete & 107 & 92 & 138 & 5,20 & 0,973 \\
\hline 42 & Un baile & 92 & 64 & 109 & 4,50 & 0,953 \\
\hline 43 & Una verdura & 56 & 44 & 66 & 5,60 & 0,920 \\
\hline 44 & Un tipo de calzado & 61 & 38 & 72 & 5,24 & 0,975 \\
\hline 45 & Un insecto & 47 & 42 & 53 & 5,59 & 0,920 \\
\hline 46 & Un nombre de mujer & 274 & 179 & 317 & 10,12 & 0,868 \\
\hline 47 & Un nombre de hombre & 220 & 147 & 259 & 10,38 & 0,915 \\
\hline 48 & Una flor & 68 & 47 & 83 & 5,28 & 0,987 \\
\hline 49 & Una enfermedad & 120 & 91 & 146 & 5,77 & 0,984 \\
\hline 50 & Un árbol & 106 & 68 & 128 & 3,50 & 0,957 \\
\hline 51 & Una embarcación & 80 & 47 & 93 & 3,97 & 0,968 \\
\hline 52 & Un pez & 86 & 57 & 101 & 5,18 & 0,952 \\
\hline 53 & Una serpiente & 46 & 30 & 57 & 3,53 & 0,984 \\
\hline 54 & Una ciudad & 158 & 111 & 196 & 7,46 & 0,973 \\
\hline 55 & Un departamento & 66 & 39 & 67 & 6,14 & 0,945 \\
\hline 56 & Una universidad & 87 & 75 & 108 & 7,19 & 0,920 \\
\hline
\end{tabular}

Como se puede apreciar en la última columna de la derecha, la correlación de Pearson realizada entre los dos grupos socioeconómicos, muestra un alto grado de correlación en todas las categorías, lo cual es ratificado por el promedio aritmético de los valores en la columna (0.964). Lo anterior implica que entre los estudiantes universitarios de Bogotá no se observan diferencias significativas en los procesos de categorización léxica según los estratos socioeconómicos. Para este análisis se usó el programa SPSS (figura 2).

De acuerdo con los datos obtenidos, la categoría que presenta la mayor variación léxica entre los estratos es la número 25 . Un condimento; sin embargo, en esta categoría se obtuvo un índice de correlación de 0,889 . La proximidad de este valor a 1 indica que a pesar de que se presentaron algunas diferencias en los rangos de las palabras de esta categoría, en general, el léxico es muy similar en ambos grupos socioeconómicos. Considerando el alto grado de correlación entre las respuestas ofrecidas por los dos grupos socioeconómicos, se procederá, de ahora en adelante, a analizar los datos de todos los sujetos conjuntamente.

\section{Comparación de los datos obtenidos en Valencia, España, con los datos obtenidos en Bogotá, Colombia}

Los resultados obtenidos en el estudio en la ciudad de Bogotá fueron comparados con uno de los estudios realizados en España, en la ciudad de Valencia (Pascual, et. al., 1980). Aunque existen estudios más recientes (Goikoetxea, 2000), el estudio de Pascual es el que resulta más directamente comparable debido a las características de la población escogida, pues los sujetos con los que trabajó Goikoetxea fueron niños. Sin embargo, Pascual no utilizó todas las categorías usadas por Battig y Montague (1969), de hecho, eliminó algunas y combinó otras, por ejemplo, las categorías bebida alcohólica y bebida no-alcohólica fueron combinadas en la categoría bebidas.

En la presente comparación, se tomaron las categorías que, a juicio de los autores, eran equivalentes. Así, se compararon 36 categorías cuyos resultados se pueden observar en la siguiente tabla. En la tercera columna está el porcentaje de respuestas que aparecen en el mismo rango de ambos corpus en los 10 primeros lugares de cada categoría. En la cuarta columna aparece el porcentaje de respuestas que se encontraban en los 10 primeros lugares de cada categoría en ambos corpus, independientemente del rango. 
Figura 3. Comparación de los datos obtenidos en Valencia, España, con los datos obtenidos en Bogotá, Colombia

\begin{tabular}{|c|c|c|c|}
\hline \multicolumn{2}{|r|}{ Categoría } & $\begin{array}{l}\text { Respuestas en el } \\
\text { mismo lugar }\end{array}$ & $\begin{array}{l}\text { Respuestas sin } \\
\text { importar el lugar }\end{array}$ \\
\hline 1 & Una piedra preciosa & $10 \%$ & $70 \%$ \\
\hline 2 & Una unidad de tiempo & $40 \%$ & $80 \%$ \\
\hline 3 & Una relación de parentesco & $0 \%$ & $80 \%$ \\
\hline 4 & Una unidad de distancia & $10 \%$ & $80 \%$ \\
\hline 5 & Un metal & $20 \%$ & $80 \%$ \\
\hline 6 & Un grado militar & $20 \%$ & $80 \%$ \\
\hline 7 & Un animal cuadrúpedo & $40 \%$ & $70 \%$ \\
\hline 8 & Un color & $40 \%$ & $60 \%$ \\
\hline 9 & Un utensilio de cocina & $20 \%$ & $70 \%$ \\
\hline 10 & Un mueble & $20 \%$ & $50 \%$ \\
\hline 11 & Una parte del cuerpo humano & $10 \%$ & $90 \%$ \\
\hline 12 & Una fruta & $10 \%$ & $50 \%$ \\
\hline 13 & Un arma & $10 \%$ & $50 \%$ \\
\hline 14 & Un país & $0 \%$ & $30 \%$ \\
\hline 15 & Un crimen & $20 \%$ & $70 \%$ \\
\hline 16 & Una herramienta de carpintería & $10 \%$ & $60 \%$ \\
\hline 17 & Un miembro del clero & $20 \%$ & $60 \%$ \\
\hline 18 & Un condimento & $0 \%$ & $50 \%$ \\
\hline 19 & Un tipo de combustible & $10 \%$ & $60 \%$ \\
\hline 20 & Una ocupación o profesión & $0 \%$ & $50 \%$ \\
\hline 21 & Un accidente geográfico & $10 \%$ & $40 \%$ \\
\hline 22 & Un deporte & $20 \%$ & $60 \%$ \\
\hline 23 & Un fenómeno climático & $0 \%$ & $40 \%$ \\
\hline 24 & Una prenda de vestir & $20 \%$ & $60 \%$ \\
\hline 25 & Una parte de un edificio & $0 \%$ & $70 \%$ \\
\hline 26 & Un instrumento musical & $40 \%$ & $70 \%$ \\
\hline 27 & Una moneda & $10 \%$ & $50 \%$ \\
\hline 28 & Un ave & $0 \%$ & $50 \%$ \\
\hline 29 & Un vehículo & $0 \%$ & $50 \%$ \\
\hline 30 & Una ciencia & $0 \%$ & $70 \%$ \\
\hline 31 & Una verdura & $10 \%$ & $50 \%$ \\
\hline 32 & Una flor & $10 \%$ & $60 \%$ \\
\hline 33 & Una enfermedad & $10 \%$ & $30 \%$ \\
\hline 34 & Un árbol & $10 \%$ & $30 \%$ \\
\hline 35 & Un pez & $0 \%$ & $50 \%$ \\
\hline 36 & Una ciudad & $0 \%$ & $10 \%$ \\
\hline
\end{tabular}

En la columna de respuestas, que compara los ítems sin importar el rango, podemos ver un alto nivel de coincidencia entre los datos obtenidos en las dos ciudades, ya que en la mayoría de los casos se observan porcentajes de correspondencia superiores al $50 \%$. Esto quiere decir que a pesar de que los estudios fueron realizados con 29 años de diferencia y en regiones bastante distantes en el 
mundo hispano, las entradas léxicas más comunes son, en buena medida, las mismas.

Sin embargo, si se observa la columna en la que se muestra la correspondencia en el rango, nos podemos dar cuenta que los porcentajes son muy bajos, con una moda de $10 \%$ y una media de $13 \%$. Esto quiere decir que, si bien las entradas léxicas son bastante similares, el nivel de tipicalidad de cada entrada no coincide en las dos ciudades. Evidentemente, en los campos semánticos con un número bajo y cerrado de entradas lexicales, el nivel de coincidencia, como era de esperarse, fue mayor, como por ejemplo en el caso de una unidad de tiempo o un color.

Hay algunos casos en los cuales el bajo o nulo nivel de coincidencia es fácilmente explicable, pues se trata de elementos léxicos estrechamente vinculados con las regiones en las que se realizaron los estudios, como en una ciudad o un país. En categorías en las cuales hay elementos que se pueden relacionar con la cultura vernácula de los sitios donde se realizaron los estudios, se puede ver una variación, tal es el caso de categorías como un árbol o una verdura, en las cuales los niveles de coincidencia son relativamente bajos (véase figura 3).

\section{Discusión}

El objetivo de este trabajo consistió en determinar las normas categoriales correspondientes al español de Bogotá, Colombia. Estas normas categoriales se recogieron siguiendo, en la medida de lo posible, el protocolo y la metodología propuestos por Battig y Montague (1969) de manera tal que los resultados puedan ser utilizados en ulteriores estudios y análisis. Además, se hizo una breve comparación de los datos obtenidos en Colombia con aquellos hallados para el español hablado en la ciudad de Valencia, España.

Los estudios de normas categoriales nos permiten captar las diferencias y similitudes entre normas en distintos lugares y en diversos idiomas; además de permitirnos establecer el inventario de los ítems lexicales más usados para cada categoría. Los resultados de esta investigación servirán, sin lugar a dudas, para la futura realización de experimentos de reconocimiento lexical y semántico, tanto en investigaciones teóricas, como en investigaciones aplicadas en el campo de la terapia del lenguaje.

En el análisis de los datos, pudimos encontrar que las entradas léxicas no muestran diferencias significativas cuando se examina la variable grupo socio-económico entre los estudiantes de diferentes universidades. Así pues, las normas categoriales son estables a través de los diversos sociolectos en la ciudad de Bogotá.

Este estudio demuestra una relativa estabilidad de las entradas léxicas halladas en el español valenciano y el español bogotano, como lo demuestra el $58 \%$ de coincidencia en las 10 primeras palabras de cada categoría, sin importar el rango. Esto resulta muy interesante, dada la distancia tanto geográfica como social de los dos corpus.

Es necesario estimular la realización de estudios similares al presente, en los cuales se examinen las normas categoriales para otros dialectos del español colombiano y latinoamericano. Además, sería altamente productivo llevar a cabo estudios comparativos entre diversos grupos etáreos y lingüísticos (por ejemplo, grupos de hablantes del español de zonas rurales, afrodescendientes, habitantes de calle, etc.) y con poblaciones con distintos niveles de instrucción. También se podría considerar la procedencia de los participantes y de su grupo familiar; sin embargo, esta variable no ha sido tomada en cuenta en ningún estudio de norma categorial de aquellos revisados en el transcurso de la investigación.

A continuación, se presentarán-por razones de espacio-45 de las 56 categorías de manera individual con la respectiva sistematización de datos. El objetivo de estas tablas es ofrecer los resultados obtenidos en cada categoría. Las palabras presentadas se organizaron según el número de veces que los sujetos las repitieron, es decir, la palabra más común aparece en la parte superior de la tabla y la menos común en la parte inferior. La información en estas tablas está organizada como se explica en la figura 4. 
Figura 4. Explicación de la tabla de resultados generales

\begin{tabular}{|c|c|c|c|}
\hline Palabra & Frecuencia & Primer Lugar & Rango \\
\hline Psmeralda & Palabra escrita por los sujetos & $\begin{array}{c}\text { Número de sujetos que escri- } \\
\text { bieron la palabra en cuestión. }\end{array}$ & $\begin{array}{c}\text { Número de sujetos que escri- } \\
\text { bieron la palabra en cuestión } \\
\text { en primer lugar cuando } \\
\text { escucharon el nombre de la } \\
\text { categoría. }\end{array}$ \\
\hline $\begin{array}{c}\text { Promedio del lugar ocupado } \\
\text { por la palabra en las listas de } \\
\text { los sujetos que la escribieron. }\end{array}$ \\
\hline
\end{tabular}

El dato numérico correspondiente al rango de las palabras, es decir, el promedio del lugar que ocupa cada palabra en la lista escrita por cada sujeto, solamente se mostrará para aquellas palabras que hayan sido escritas por 10 informantes o más, en una categoría determinada. No se incluyen en estas tablas las palabras escritas por menos de 10 informantes.

\begin{tabular}{|l|c|c|c|}
\hline \multicolumn{4}{|c|}{ 1. Una piedra preciosa } \\
\hline \multicolumn{1}{|c|}{ Palabra } & Frecuencia & Primer Lugar & Rango \\
\hline Esmeralda & 196 & 92 & 1,97 \\
\hline Diamante & 175 & 43 & 2,63 \\
\hline Rubí & 162 & 48 & 2,12 \\
\hline Zafiro & 83 & 7 & 3,31 \\
\hline Perla & 49 & 4 & 3,45 \\
\hline Amatista & 31 & 2 & 4,00 \\
\hline Cuarzo & 27 & 2 & 3,78 \\
\hline Topacio & 21 & 1 & 3,67 \\
\hline Ónix & 16 & 3 & 3,50 \\
\hline Ópalo & 12 & 0 & 4,50 \\
\hline Oro & 12 & 0 & 3,83 \\
\hline Jade & 11 & 2 & 2,73 \\
\hline Zircón & 11 & 0 & 3,55 \\
\hline
\end{tabular}

\begin{tabular}{|l|c|c|c|}
\hline \multicolumn{4}{|c|}{ 2. Una unidad de tiempo } \\
\hline \multicolumn{1}{|c|}{ Palabra } & Frecuencia & Primer Lugar & Rango \\
\hline Segundo & 195 & 89 & 1,92 \\
\hline Hora & 193 & 47 & 2,51 \\
\hline Minuto & 190 & 56 & 1,95 \\
\hline Año & 88 & 0 & 5,60 \\
\hline Día & 81 & 1 & 4,75 \\
\hline Mes & 66 & 1 & 5,20 \\
\hline Milésima & 66 & 3 & 4,09 \\
\hline
\end{tabular}

\begin{tabular}{|l|l|l|l|}
\hline Siglo & 47 & 0 & 7,02 \\
\hline Semana & 40 & 0 & 5,55 \\
\hline Centésima & 34 & 0 & 4,82 \\
\hline Milenio & 34 & 0 & 8,00 \\
\hline Década & 31 & 0 & 7,13 \\
\hline Milisegundo & 17 & 1 & 5,18 \\
\hline Cuarto & 10 & 1 & 4,70 \\
\hline
\end{tabular}

\begin{tabular}{|l|c|c|c|}
\hline \multicolumn{4}{|c|}{ 3. Una relación de parentesco } \\
\hline \multicolumn{1}{|c|}{ Palabra } & Frecuencia & Primer Lugar & Rango \\
\hline Tío & 164 & 24 & 3,79 \\
\hline Primo & 154 & 27 & 4,13 \\
\hline Hermano & 153 & 32 & 3,44 \\
\hline Abuelo & 149 & 6 & 4,90 \\
\hline Sobrino & 122 & 2 & 5,43 \\
\hline Padre & 121 & 54 & 2,33 \\
\hline Hijo & 102 & 16 & 3,61 \\
\hline Madre & 78 & 6 & 3,12 \\
\hline Cuñado & 58 & 0 & 6,43 \\
\hline Mamá & 52 & 7 & 3,37 \\
\hline Papá & 52 & 12 & 2,92 \\
\hline Nieto & 45 & 0 & 6,73 \\
\hline Esposo & 31 & 0 & 6,26 \\
\hline Suegro & 27 & 0 & 7,89 \\
\hline Novio & 23 & 4 & 5,04 \\
\hline Bisabuelo & 12 & 0 & 7,08 \\
\hline Amigo & 10 & 2 & 4,60 \\
\hline Nuera & 10 & 0 & 8,30 \\
\hline
\end{tabular}

\begin{tabular}{|l|c|c|c|}
\hline \multicolumn{4}{|c|}{ 4. Una unidad de distancia } \\
\hline \multicolumn{1}{|c|}{ Palabra } & Frecuencia & Primer Lugar & Rango \\
\hline Kilómetro & 194 & 87 & 2,20 \\
\hline Metro & 191 & 84 & 1,87 \\
\hline Centímetro & 124 & 14 & 3,14 \\
\hline \multicolumn{4}{|c}{ Continúa }
\end{tabular}




\begin{tabular}{|l|c|l|l|}
\hline Milla & 120 & 7 & 3,42 \\
\hline Milímetro & 68 & 6 & 4,35 \\
\hline Yarda & 44 & 2 & 4,16 \\
\hline Pie & 42 & 0 & 4,64 \\
\hline Pulgada & 35 & 2 & 4,29 \\
\hline Decámetro & 34 & 0 & 4,53 \\
\hline Decímetro & 27 & 0 & 4,67 \\
\hline Hectómetro & 20 & 0 & 4,40 \\
\hline Legua & 13 & 0 & 5,15 \\
\hline Hectárea & 10 & 0 & 4,20 \\
\hline
\end{tabular}

\begin{tabular}{|l|l|l|l|}
\hline Diario & 12 & 0 & 4,83 \\
\hline Pancarta & 12 & 0 & 5,58 \\
\hline Valla & 12 & 0 & 5,25 \\
\hline Volante & 11 & 0 & 5,00 \\
\hline
\end{tabular}

\section{Un metal}

\begin{tabular}{|l|c|c|c|}
\hline \multicolumn{1}{|c|}{ Palabra } & Frecuencia & Primer Lugar & Rango \\
\hline Hierro & 135 & 70 & 2,23 \\
\hline Cobre & 110 & 13 & 3,13 \\
\hline Plata & 107 & 17 & 2,88 \\
\hline Oro & 103 & 40 & 2,62 \\
\hline Aluminio & 83 & 15 & 3,23 \\
\hline Bronce & 69 & 8 & 3,16 \\
\hline Acero & 55 & 13 & 3,36 \\
\hline Platino & 22 & 2 & 4,09 \\
\hline Mercurio & 14 & 2 & 3,29 \\
\hline Estaño & 13 & 1 & 4,54 \\
\hline Níquel & 10 & 1 & 4,90 \\
\hline Titanio & 10 & 1 & 5,10 \\
\hline Zinc & 10 & 0 & 4,40 \\
\hline
\end{tabular}

\begin{tabular}{|l|c|c|c|}
\hline \multicolumn{4}{|c|}{ 6. Un material de lectura } \\
\hline \multicolumn{1}{|c|}{ Palabra } & Frecuencia & Primer Lugar & Rango \\
\hline Libro & 198 & 152 & 1,36 \\
\hline Revista & 157 & 17 & 2,52 \\
\hline Periódico & 138 & 18 & 3,11 \\
\hline Cuaderno & 51 & 0 & 3,75 \\
\hline Cuento & 31 & 0 & 3,97 \\
\hline Fotocopia & 30 & 5 & 3,20 \\
\hline Folleto & 28 & 0 & 4,00 \\
\hline Enciclopedia & 25 & 0 & 4,08 \\
\hline Artículo & 24 & 2 & 3,96 \\
\hline Ensayo & 24 & 2 & 4,04 \\
\hline Carta & 22 & 1 & 4,50 \\
\hline Diccionario & 17 & 0 & 4,53 \\
\hline Novela & 17 & 1 & 3,88 \\
\hline Internet & 16 & 0 & 4,25 \\
\hline Cómic & 14 & 1 & 3,86 \\
\hline
\end{tabular}

\begin{tabular}{|l|c|c|c|}
\hline \multicolumn{5}{|c|}{ 7. Un grado militar } \\
\hline \multicolumn{1}{|c|}{ Palabra } & Frecuencia & Primer Lugar & Rango \\
\hline Teniente & 139 & 50 & 2,48 \\
\hline General & 128 & 32 & 3,26 \\
\hline Cabo & 116 & 19 & 3,19 \\
\hline Soldado & 105 & 16 & 3,80 \\
\hline Sargento & 103 & 34 & 2,55 \\
\hline Coronel & 101 & 22 & 3,05 \\
\hline Capitán & 80 & 7 & 3,64 \\
\hline Comandante & 62 & 8 & 3,61 \\
\hline Mayor & 59 & 8 & 3,58 \\
\hline Subteniente & 46 & 1 & 3,91 \\
\hline Oficial & 21 & 1 & 3,62 \\
\hline Suboficial & 17 & 1 & 3,53 \\
\hline Dragoneante & 13 & 3 & 4,38 \\
\hline Patrullero & 12 & 0 & 4,75 \\
\hline Almirante & 11 & 0 & 5,36 \\
\hline Policía & 11 & 0 & 4,64 \\
\hline Alférez & 10 & 1 & 4,10 \\
\hline Cadete & 10 & 4 & 3,50 \\
\hline
\end{tabular}

\begin{tabular}{|l|c|c|c|}
\hline \multicolumn{4}{|c|}{ 8. Un animal cuadrúpedo } \\
\hline \multicolumn{1}{|c|}{ Palabra } & Frecuencia & Primer Lugar & Rango \\
\hline Perro & 210 & 139 & 1,60 \\
\hline Gato & 198 & 19 & 2,73 \\
\hline Vaca & 149 & 23 & 3,63 \\
\hline Caballo & 138 & 11 & 4,14 \\
\hline León & 122 & 8 & 5,13 \\
\hline Tigre & 100 & 3 & 5,58 \\
\hline Elefante & 92 & 2 & 5,93 \\
\hline Jirafa & 71 & 1 & 5,97 \\
\hline Burro & 46 & 0 & 5,35 \\
\hline Cebra & 43 & 0 & 5,98 \\
\hline Toro & 33 & 0 & 5,39 \\
\hline Ratón & 27 & 1 & 5,67 \\
\hline Conejo & 26 & 1 & 6,04 \\
\hline Pantera & 26 & 0 & 6,96 \\
\hline Cerdo & 24 & 0 & 5,08 \\
\hline Hipopótamo & 24 & 0 & 7,04 \\
\hline & & & Continúa \\
\hline
\end{tabular}




\begin{tabular}{|l|l|l|l|}
\hline Zorro & 24 & 0 & 6,58 \\
\hline Cabra & 23 & 0 & 5,65 \\
\hline Rinoceronte & 22 & 0 & 6,09 \\
\hline Oveja & 20 & 0 & 5,60 \\
\hline Leopardo & 18 & 0 & 7,28 \\
\hline Oso & 18 & 0 & 6,61 \\
\hline Hiena & 17 & 0 & 6,94 \\
\hline Lobo & 15 & 0 & 6,67 \\
\hline Puma & 12 & 0 & 6,67 \\
\hline Camello & 10 & 0 & 5,50 \\
\hline
\end{tabular}

\begin{tabular}{|l|c|c|c|}
\hline \multicolumn{5}{|c|}{ 9. Un tipo de tela } \\
\hline \multicolumn{1}{|c|}{ Palabra } & Frecuencia & Primer Lugar & Rango \\
\hline Seda & 150 & 78 & 2,13 \\
\hline Algodón & 117 & 21 & 2,84 \\
\hline Lino & 76 & 22 & 2,33 \\
\hline Jean & 72 & 3 & 3,58 \\
\hline Lana & 65 & 7 & 3,52 \\
\hline Paño & 64 & 7 & 3,56 \\
\hline Licra & 51 & 7 & 3,33 \\
\hline Poliéster & 47 & 9 & 3,51 \\
\hline Pana & 43 & 1 & 3,84 \\
\hline Dril & 41 & 5 & 3,73 \\
\hline Dacrón & 34 & 15 & 2,41 \\
\hline Nylon & 26 & 8 & 2,54 \\
\hline Satín & 26 & 8 & 2,96 \\
\hline Terciopelo & 26 & 3 & 3,77 \\
\hline Gamuza & 16 & 0 & 4,25 \\
\hline Cuero & 14 & 0 & 5,21 \\
\hline
\end{tabular}

\begin{tabular}{|l|c|c|c|}
\hline \multicolumn{5}{|c|}{ 10. Un color } \\
\hline \multicolumn{1}{|c|}{ Palabra } & Frecuencia & Primer Lugar & Rango \\
\hline Azul & 204 & 76 & 2,47 \\
\hline Amarillo & 200 & 52 & 3,45 \\
\hline Rojo & 200 & 41 & 3,03 \\
\hline Verde & 195 & 11 & 4,34 \\
\hline Negro & 194 & 13 & 5,19 \\
\hline Blanco & 169 & 8 & 5,58 \\
\hline Morado & 124 & 2 & 6,27 \\
\hline Rosado & 110 & 3 & 6,89 \\
\hline Café & 104 & 0 & 7,56 \\
\hline Gris & 101 & 0 & 7,47 \\
\hline Naranja & 92 & 0 & 7,00 \\
\hline Violeta & 62 & 0 & 7,81 \\
\hline
\end{tabular}

\begin{tabular}{|l|l|l|l|}
\hline Fucsia & 40 & 1 & 8,45 \\
\hline Anaranjado & 32 & 1 & 7,06 \\
\hline Púrpura & 27 & 0 & 7,70 \\
\hline Beige & 16 & 0 & 8,75 \\
\hline Marrón & 16 & 0 & 8,50 \\
\hline Dorado & 14 & 0 & 8,50 \\
\hline Lila & 13 & 0 & 8,69 \\
\hline Plateado & 13 & 0 & 9,00 \\
\hline Vino tinto & 10 & 0 & 8,70 \\
\hline
\end{tabular}

\begin{tabular}{|l|c|c|c|}
\hline \multicolumn{5}{|c|}{ 11. Utensilio de cocina } \\
\hline \multicolumn{1}{|c|}{ Palabra } & Frecuencia & Primer Lugar & Rango \\
\hline Olla & 177 & 44 & 3,00 \\
\hline Cuchara & 175 & 68 & 2,49 \\
\hline Cuchillo & 167 & 48 & 2,92 \\
\hline Tenedor & 137 & 9 & 3,51 \\
\hline Plato & 94 & 7 & 4,51 \\
\hline Sartén & 77 & 12 & 3,92 \\
\hline Vaso & 49 & 0 & 6,06 \\
\hline Licuadora & 42 & 4 & 5,12 \\
\hline Estufa & 41 & 2 & 5,17 \\
\hline Cucharón & 40 & 6 & 4,18 \\
\hline Tabla para picar & 34 & 0 & 5,44 \\
\hline Pocillo & 33 & 0 & 6,48 \\
\hline Molinillo & 29 & 1 & 5,41 \\
\hline Paila & 26 & 0 & 4,73 \\
\hline Colador & 22 & 1 & 4,68 \\
\hline Jarra & 21 & 0 & 5,90 \\
\hline Limpión & 18 & 0 & 5,33 \\
\hline Horno & 17 & 0 & 7,29 \\
\hline Olleta & 17 & 1 & 5,53 \\
\hline Batidora & 16 & 0 & 5,88 \\
\hline Espátula & 16 & 2 & 4,94 \\
\hline Tapa & 13 & 1 & 6,20 \\
\hline Nevera & 11 & 0 & 6,86 \\
\hline Exprimidor & & 0 & 5,46 \\
\hline Cubiertos & Rallador & 3,91 \\
\hline
\end{tabular}

\begin{tabular}{|l|c|c|c|}
\hline \multicolumn{3}{|c|}{ 12. Un edificio para servicios religiosos } \\
\hline Palabra & Frecuencia & Primer Lugar & Rango \\
\hline Iglesia & 189 & 157 & 1,21 \\
\hline Templo & 73 & 8 & 2,68 \\
\hline Capilla & 52 & 5 & 2,87 \\
\hline \multicolumn{4}{|c}{ Continúa }
\end{tabular}




\begin{tabular}{|l|l|l|l|}
\hline Catedral & 44 & 5 & 2,84 \\
\hline Mezquita & 40 & 4 & 2,63 \\
\hline Sinagoga & 29 & 5 & 2,72 \\
\hline Monasterio & 27 & 2 & 2,78 \\
\hline Convento & 21 & 1 & 2,95 \\
\hline Parroquia & 19 & 2 & 2,74 \\
\hline
\end{tabular}

\begin{tabular}{|c|c|c|c|}
\hline \multicolumn{4}{|c|}{ 15. Una parte del cuerpo humano } \\
\hline Palabra & Frecuencia & Primer Lugar & Rango \\
\hline Pie & 165 & 4 & 5,50 \\
\hline Pierna & 157 & 7 & 4,83 \\
\hline Cabeza & 149 & 56 & 3,03 \\
\hline Manos & 146 & 27 & 4,47 \\
\hline Ojo & 144 & 41 & 4,24 \\
\hline Brazo & 141 & 35 & 3,80 \\
\hline Dedos & 114 & 2 & 6,34 \\
\hline Nariz & 93 & 3 & 6,05 \\
\hline Boca & 92 & 3 & 5,91 \\
\hline Oreja & 73 & 4 & 6,70 \\
\hline Rodilla & 56 & 1 & 7,09 \\
\hline Cuello & 53 & 1 & 6,74 \\
\hline Hombros & 46 & 3 & 4,76 \\
\hline Uñas & 46 & 0 & 8,26 \\
\hline Espalda & 39 & 0 & 8,10 \\
\hline Estómago & 37 & 0 & 6,76 \\
\hline Pecho & 37 & 0 & 7,16 \\
\hline Cara & 36 & 15 & 2,92 \\
\hline Codo & 29 & 0 & 8,38 \\
\hline Corazón & 26 & 1 & 6,23 \\
\hline Tronco & 25 & 0 & 4,88 \\
\hline Cabello & 20 & 0 & 7,60 \\
\hline Cadera & 20 & 0 & 8,80 \\
\hline Cola & 19 & 0 & 7,42 \\
\hline Abdomen & 16 & 1 & 6,19 \\
\hline Cintura & 16 & 0 & 7,75 \\
\hline Dientes & 16 & 0 & 8,31 \\
\hline Oído & 16 & 1 & 5,25 \\
\hline Labios & 12 & 0 & 4,42 \\
\hline Pelo & 12 & 1 & 6,00 \\
\hline Hígado & 11 & 0 & 8,91 \\
\hline Ceja & 11 & 0 & 8,82 \\
\hline Cerebro & 11 & 2 & 5,09 \\
\hline Lengua & 11 & 0 & 7,45 \\
\hline Tobillo & 11 & 0 & 9,09 \\
\hline Ombligo & 10 & 0 & 7,60 \\
\hline Pene & 10 & 1 & 5,10 \\
\hline Senos & 10 & 0 & 6,10 \\
\hline
\end{tabular}

\begin{tabular}{|l|c|c|c|}
\hline \multicolumn{5}{|c|}{ 14. Un mueble } \\
\hline \multicolumn{1}{|c|}{ Palabra } & Frecuencia & Primer Lugar & Rango \\
\hline Silla & 181 & 86 & 2,09 \\
\hline Sofá & 159 & 66 & 2,19 \\
\hline Mesa & 157 & 23 & 3,16 \\
\hline Cama & 140 & 16 & 3,42 \\
\hline Armario & 73 & 2 & 4,49 \\
\hline Escritorio & 49 & 0 & 4,55 \\
\hline Comedor & 48 & 0 & 4,54 \\
\hline Mesa de noche & 46 & 1 & 5,11 \\
\hline Tocador & 36 & 0 & 4,97 \\
\hline Bifé & 34 & 2 & 5,06 \\
\hline Sillón & 30 & 4 & 2,77 \\
\hline Closet & 28 & 1 & 4,07 \\
\hline Sofácama & 23 & 0 & 4,17 \\
\hline Biblioteca & 19 & 1 & 5,42 \\
\hline Mecedora & 14 & 0 & 4,43 \\
\hline Poltrona & 14 & 1 & 5,00 \\
\hline Butaca & 13 & 0 & 4,00 \\
\hline Pupitre & 12 & 2 & 4,50 \\
\hline
\end{tabular}




\begin{tabular}{|c|c|c|c|}
\hline \multicolumn{4}{|c|}{ 16. Una fruta } \\
\hline Palabra & Frecuencia & Primer Lugar & Rango \\
\hline Manzana & 176 & 81 & 2,44 \\
\hline Pera & 131 & 25 & 3,34 \\
\hline Banano & 112 & 10 & 5,42 \\
\hline Naranja & 111 & 11 & 5,06 \\
\hline Fresa & 111 & 9 & 5,44 \\
\hline Mandarina & 85 & 8 & 5,54 \\
\hline Melón & 85 & 10 & 5,08 \\
\hline Mora & 84 & 5 & 5,79 \\
\hline Uva & 82 & 4 & 5,45 \\
\hline Papaya & 80 & 1 & 5,73 \\
\hline Piña & 75 & 7 & 4,23 \\
\hline Durazno & 73 & 3 & 5,00 \\
\hline Limón & 68 & 2 & 5,50 \\
\hline Mango & 65 & 12 & 4,49 \\
\hline Guayaba & 45 & 0 & 6,47 \\
\hline Guanábana & 44 & 3 & 6,59 \\
\hline Sandía & 44 & 2 & 5,73 \\
\hline Patilla & 38 & 1 & 5,97 \\
\hline Kiwi & 36 & 1 & 6,78 \\
\hline Lulo & 36 & 0 & 6,31 \\
\hline Maracuyá & 34 & 0 & 7,59 \\
\hline Granadilla & 33 & 0 & 6,55 \\
\hline Cereza & 32 & 2 & 6,84 \\
\hline Ciruela & 27 & 2 & 6,52 \\
\hline Feijoa & 22 & 0 & 7,68 \\
\hline Melocotón & 20 & 2 & 5,85 \\
\hline Coco & 19 & 0 & 6,32 \\
\hline Anón & 18 & 2 & 5,61 \\
\hline Curuba & 16 & 0 & 7,25 \\
\hline Zapote & 16 & 1 & 6,19 \\
\hline Frambuesa & 14 & 0 & 7,79 \\
\hline Lima & 14 & 1 & 6,00 \\
\hline Mamoncillo & 11 & 0 & 6,09 \\
\hline Pitahaya & 11 & 0 & 6,27 \\
\hline
\end{tabular}

\begin{tabular}{|l|c|c|c|}
\hline Navaja & 62 & 7 & 3,16 \\
\hline Fusil & 51 & 11 & 3,24 \\
\hline Bazuca & 46 & 1 & 4,46 \\
\hline Granada & 46 & 0 & 4,74 \\
\hline Ametralladora & 43 & 3 & 3,72 \\
\hline Rifle & 36 & 8 & 3,19 \\
\hline Cañón & 32 & 2 & 3,94 \\
\hline Bomba & 28 & 0 & 4,89 \\
\hline Espada & 23 & 4 & 4,35 \\
\hline Misil & 15 & 0 & 5,00 \\
\hline Puñal & 14 & 2 & 4,57 \\
\hline Machete & 12 & 0 & 4,58 \\
\hline Tanque & 12 & 0 & 4,33 \\
\hline Lanzacohetes & 10 & 1 & 4,70 \\
\hline Lanzagranadas & 10 & 0 & 5,50 \\
\hline
\end{tabular}

\begin{tabular}{|l|c|c|c|}
\hline \multicolumn{4}{|c|}{ 18. Un cargo de eleccion popular } \\
\hline \multicolumn{1}{|c|}{ Palabra } & Frecuencia & Primer lugar & Rango \\
\hline Presidente & 199 & 122 & 1,74 \\
\hline Alcalde & 190 & 61 & 2,14 \\
\hline Gobernador & 98 & 6 & 3,41 \\
\hline Concejal & 97 & 5 & 3,16 \\
\hline Senador & 91 & 7 & 3,46 \\
\hline Edil & 66 & 5 & 3,64 \\
\hline Representante & 57 & 0 & 4,70 \\
\hline Personero & 42 & 1 & 4,29 \\
\hline Ministro & 36 & 1 & 3,83 \\
\hline Congresista & 29 & 2 & 3,93 \\
\hline Vicepresidente & 17 & 0 & 3,65 \\
\hline Diputado & 14 & 0 & 4,07 \\
\hline
\end{tabular}

\begin{tabular}{|l|c|c|c|}
\hline \multicolumn{4}{|c|}{ 19. Un tipo de vivienda } \\
\hline \multicolumn{1}{|c|}{ Palabra } & Frecuencia & Primer lugar & Rango \\
\hline Casa & 202 & 158 & 1,30 \\
\hline Apartamento & 191 & 26 & 2,10 \\
\hline Choza & 81 & 5 & 3,72 \\
\hline Finca & 76 & 1 & 3,62 \\
\hline Edificio & 37 & 6 & 3,05 \\
\hline Mansión & 32 & 1 & 3,94 \\
\hline Cabaña & 31 & 0 & 4,29 \\
\hline Apartaestudio & 30 & 0 & 4,17 \\
\hline Hotel & 24 & 0 & 4,21 \\
\hline Iglú & 21 & 2 & 3,81 \\
\hline \multicolumn{4}{|c|}{} \\
\hline
\end{tabular}




\begin{tabular}{|l|l|l|l|}
\hline Penthouse & 19 & 1 & 3,37 \\
\hline Cambuche & 14 & 0 & 4,21 \\
\hline Carpa & 12 & 0 & 5,67 \\
\hline Castillo & 12 & 0 & 4,33 \\
\hline Hacienda & 12 & 0 & 4,25 \\
\hline Cueva & 11 & 1 & 4,73 \\
\hline Quinta & 10 & 1 & 4,00 \\
\hline
\end{tabular}

\begin{tabular}{|l|l|l|l|}
\hline Rusia & 39 & 0 & 6,44 \\
\hline Bolivia & 38 & 0 & 6,63 \\
\hline Australia & 29 & 1 & 5,45 \\
\hline Panamá & 29 & 0 & 6,34 \\
\hline EEUU & 25 & 1 & 4,72 \\
\hline Uruguay & 24 & 0 & 7,38 \\
\hline Suiza & 16 & 0 & 5,81 \\
\hline Cuba & 15 & 0 & 6,07 \\
\hline Paraguay & 14 & 0 & 7,00 \\
\hline Suecia & 14 & 0 & 6,71 \\
\hline Holanda & 13 & 4 & 4,77 \\
\hline India & 12 & 1 & 6,75 \\
\hline Guatemala & 11 & 0 & 5,91 \\
\hline Grecia & 10 & 0 & 7,20 \\
\hline
\end{tabular}

\begin{tabular}{|l|c|c|c|}
\hline \multicolumn{4}{|c|}{ 20. Una bebida alcohólica } \\
\hline \multicolumn{1}{|c|}{ Palabra } & Frecuencia & Primer Lugar & Rango \\
\hline Cerveza & 187 & 99 & 2,29 \\
\hline Aguardiente & 186 & 36 & 2,83 \\
\hline Ron & 167 & 29 & 2,95 \\
\hline Whisky & 165 & 17 & 3,83 \\
\hline Vodka & 125 & 11 & 3,85 \\
\hline Vino & 107 & 7 & 4,07 \\
\hline Tequila & 64 & 2 & 4,80 \\
\hline Brandy & 36 & 1 & 4,94 \\
\hline Ginebra & 33 & 0 & 4,91 \\
\hline Chicha & 30 & 0 & 5,70 \\
\hline Cóctel & 21 & 0 & 5,52 \\
\hline Champaña & 14 & 0 & 5,14 \\
\hline Guarapo & 13 & 0 & 5,85 \\
\hline Chin chin & 11 & 0 & 5,73 \\
\hline
\end{tabular}

\begin{tabular}{|l|c|c|c|}
\hline \multicolumn{5}{|c|}{ 21. Un país } \\
\hline Palabra & Frecuencia & Primer Lugar & Rango \\
\hline Colombia & 193 & 146 & 1,80 \\
\hline Argentina & 117 & 7 & 5,26 \\
\hline Francia & 109 & 4 & 5,30 \\
\hline Perú & 105 & 3 & 4,90 \\
\hline Venezuela & 102 & 3 & 4,64 \\
\hline Brasil & 93 & 2 & 4,84 \\
\hline Ecuador & 84 & 3 & 5,49 \\
\hline España & 70 & 1 & 5,73 \\
\hline Chile & 62 & 2 & 6,24 \\
\hline Alemania & 62 & 15 & 4,02 \\
\hline México & 59 & 0 & 6,14 \\
\hline China & 57 & 2 & 6,60 \\
\hline Canadá & 54 & 3 & 5,41 \\
\hline Estados unidos & 54 & 3 & 4,96 \\
\hline Italia & 49 & 1 & 5,98 \\
\hline Inglaterra & 47 & 2 & 5,47 \\
\hline Japón & 42 & 1 & 6,62 \\
\hline & & & Continúa \\
\hline
\end{tabular}

\begin{tabular}{|l|c|c|c|}
\hline \multicolumn{5}{|c|}{ 22. Un crimen } \\
\hline \multicolumn{1}{|c|}{ Palabra } & Frecuencia & Primer Lugar & Rango \\
\hline Asesinato & 144 & 109 & 1,42 \\
\hline Violación & 139 & 21 & 2,58 \\
\hline Robo & 125 & 14 & 2,52 \\
\hline Secuestro & 58 & 3 & 3,62 \\
\hline Homicidio & 41 & 18 & 2,10 \\
\hline Estafa & 21 & 0 & 4,62 \\
\hline Hurto & 21 & 2 & 3,14 \\
\hline Matar & 21 & 12 & 1,81 \\
\hline Asalto & 19 & 6 & 2,42 \\
\hline Suicidio & 19 & 4 & 2,79 \\
\hline Maltrato & 16 & 0 & 4,38 \\
\hline Extorsión & 14 & 0 & 4,29 \\
\hline Genocidio & 12 & 1 & 3,67 \\
\hline
\end{tabular}

\begin{tabular}{|l|c|c|c|}
\hline \multicolumn{4}{|c|}{ 23. Una herramienta de carpintería } \\
\hline \multicolumn{1}{|c|}{ Palabra } & Frecuencia & Primer Lugar & Rango \\
\hline Martillo & 184 & 130 & 1,67 \\
\hline Serrucho & 146 & 34 & 2,66 \\
\hline Puntilla & 104 & 3 & 3,70 \\
\hline Lija & 71 & 6 & 4,20 \\
\hline Madera & 61 & 5 & 3,95 \\
\hline Sierra & 53 & 2 & 3,55 \\
\hline Clavo & 41 & 0 & 3,80 \\
\hline Taladro & 40 & 5 & 3,58 \\
\hline Destornillador & 38 & 0 & 4,18 \\
\hline Segueta & 33 & 3 & 3,76 \\
\hline Pulidora & 28 & 1 & 3,93 \\
\hline \multicolumn{4}{|c|}{} \\
\end{tabular}




\begin{tabular}{|l|l|l|l|}
\hline Tornillo & 27 & 0 & 4,74 \\
\hline Cincel & 25 & 1 & 3,00 \\
\hline Cepillo & 23 & 7 & 2,48 \\
\hline Cortadora & 22 & 1 & 3,86 \\
\hline Pegante & 22 & 0 & 4,73 \\
\hline Alicate & 20 & 0 & 4,95 \\
\hline metro & 17 & 2 & 4,35 \\
\hline pintura & 13 & 1 & 4,77 \\
\hline regla & 12 & 0 & 4,50 \\
\hline
\end{tabular}

\begin{tabular}{|l|c|c|c|}
\hline \multicolumn{4}{|c|}{ 24. Un miembro del clero } \\
\hline \multicolumn{1}{|c|}{ Palabra } & Frecuencia & Primer Lugar & Rango \\
\hline Papa & 155 & 59 & 2,36 \\
\hline Obispo & 125 & 26 & 2,47 \\
\hline Sacerdote & 106 & 47 & 2,27 \\
\hline Cura & 75 & 22 & 2,37 \\
\hline Monja & 57 & 4 & 3,75 \\
\hline Padre & 45 & 17 & 2,29 \\
\hline Cardenal & 41 & 1 & 3,59 \\
\hline Arzobispo & 39 & 2 & 3,23 \\
\hline Monseñor & 25 & 0 & 4,24 \\
\hline Seminarista & 14 & 0 & 4,36 \\
\hline Sacristán & 13 & 0 & 3,85 \\
\hline Monaguillo & 12 & 0 & 4,58 \\
\hline Pastor & 10 & 2 & 3,30 \\
\hline
\end{tabular}

\begin{tabular}{|l|c|c|c|}
\hline \multicolumn{5}{|c|}{ 25. Un condimento } \\
\hline \multicolumn{1}{|c|}{ Palabra } & Frecuencia & Primer Lugar & Rango \\
\hline Pimienta & 167 & 41 & 2,62 \\
\hline Color & 129 & 32 & 2,84 \\
\hline Sal & 129 & 52 & 2,52 \\
\hline Comino & 99 & 21 & 2,71 \\
\hline Ajo & 88 & 14 & 3,57 \\
\hline Tomillo & 57 & 2 & 4,09 \\
\hline Laurel & 46 & 0 & 4,89 \\
\hline Ají & 37 & 12 & 2,68 \\
\hline Orégano & 34 & 4 & 3,50 \\
\hline Azúcar & 23 & 1 & 3,61 \\
\hline Páprika & 22 & 6 & 3,18 \\
\hline Canela & 21 & 1 & 4,67 \\
\hline Salsina & 19 & 7 & 2,63 \\
\hline Cebolla & 18 & 2 & 4,28 \\
\hline Salsa & 14 & 1 & 4,14 \\
\hline Clavo & 13 & 0 & 4,62 \\
\hline & & & Continúa \\
\hline
\end{tabular}

\begin{tabular}{|l|l|l|l|}
\hline Perejil & 11 & 2 & 4,18 \\
\hline Azafrán & 10 & 2 & 4,40 \\
\hline Pimentón & 10 & 3 & 2,70 \\
\hline
\end{tabular}

\begin{tabular}{|l|c|c|c|}
\hline \multicolumn{5}{|c|}{ 26. Un tipo de combustible } \\
\hline \multicolumn{1}{|c|}{ Palabra } & Frecuencia & Primer Lugar & Rango \\
\hline Gasolina & 200 & 137 & 1,41 \\
\hline Gas & 154 & 31 & 2,45 \\
\hline ACPM & 94 & 11 & 2,78 \\
\hline Petróleo & 76 & 9 & 3,03 \\
\hline Diesel & 61 & 11 & 2,70 \\
\hline Alcohol & 35 & 0 & 4,26 \\
\hline Carbón & 26 & 2 & 3,31 \\
\hline Aceite & 20 & 5 & 3,00 \\
\hline Etanol & 16 & 0 & 3,56 \\
\hline Agua & 15 & 0 & 4,33 \\
\hline Biodiesel & 11 & 0 & 3,73 \\
\hline Energía & 10 & 0 & 4,50 \\
\hline
\end{tabular}

\begin{tabular}{|l|c|c|c|}
\hline \multicolumn{4}{|c|}{ 27. Una profesión u oficio } \\
\hline Palabra & Frecuencia & Primer Lugar & Rango \\
\hline Profesor & 150 & 64 & 2,36 \\
\hline Abogado & 102 & 17 & 3,22 \\
\hline Ingeniero & 97 & 7 & 4,06 \\
\hline Médico & 74 & 20 & 2,93 \\
\hline Doctor & 64 & 13 & 3,31 \\
\hline Enfermero & 50 & 5 & 4,52 \\
\hline Secretaria & 48 & 11 & 3,90 \\
\hline Arquitecto & 41 & 4 & 3,78 \\
\hline Administrador & 39 & 3 & 4,97 \\
\hline Estudiante & 31 & 10 & 3,16 \\
\hline Contador & 28 & 2 & 4,25 \\
\hline Psicólogo & 27 & 1 & 4,85 \\
\hline Carpintero & 24 & 3 & 4,29 \\
\hline Diseñador & 24 & 2 & 5,21 \\
\hline Policía & 24 & 2 & 4,21 \\
\hline Economista & 19 & 0 & 5,74 \\
\hline Odontólogo & 19 & 1 & 5,11 \\
\hline Músico & 18 & 6 & 4,22 \\
\hline Vendedor & 18 & 0 & 5,39 \\
\hline Traductor & 17 & 2 & 3,65 \\
\hline Comerciante & 16 & 1 & 4,88 \\
\hline Conductor & 15 & 0 & 5,60 \\
\hline Escritor & 15 & 0 & 4,73 \\
\hline & & & Continúa \\
\hline
\end{tabular}




\begin{tabular}{|l|l|l|l|}
\hline Ama de casa & 14 & 0 & 5,21 \\
\hline Gerente & 14 & 2 & 4,50 \\
\hline Periodista & 14 & 0 & 6,93 \\
\hline Presidente & 13 & 0 & 4,77 \\
\hline Actor & 12 & 1 & 6,67 \\
\hline Bombero & 12 & 2 & 3,50 \\
\hline Lingüista & 11 & 0 & 3,82 \\
\hline Docente & 10 & 4 & 2,50 \\
\hline Filólogo & 10 & 4 & 2,00 \\
\hline
\end{tabular}

\begin{tabular}{|l|l|l|l|}
\hline Baseball & 37 & 4 & 3,62 \\
\hline Ping pong & 36 & 0 & 5,58 \\
\hline Golf & 26 & 0 & 4,65 \\
\hline Boxeo & 22 & 0 & 5,32 \\
\hline Pesas & 20 & 0 & 5,55 \\
\hline Billar & 16 & 0 & 5,19 \\
\hline Judo & 16 & 1 & 4,56 \\
\hline Equitación & 15 & 1 & 4,93 \\
\hline Esgrima & 15 & 1 & 4,93 \\
\hline Squash & 15 & 1 & 5,47 \\
\hline Karate & 14 & 1 & 4,86 \\
\hline Tejo & 14 & 2 & 4,07 \\
\hline Tiro & 12 & 0 & 5,17 \\
\hline Bolos & 11 & 0 & 5,45 \\
\hline Rugby & 10 & 0 & 4,20 \\
\hline Taekwondo & 10 & 3 & 3,30 \\
\hline
\end{tabular}

\begin{tabular}{|l|c|c|c|}
\hline \multicolumn{4}{|c|}{ 28. Un accidente geográfico } \\
\hline Palabra & Frecuencia & Primer Lugar & Rango \\
\hline Montaña & 81 & 43 & 1,95 \\
\hline Meseta & 64 & 16 & 2,89 \\
\hline Cordillera & 53 & 10 & 3,15 \\
\hline Volcán & 43 & 13 & 2,81 \\
\hline Valle & 34 & 6 & 2,88 \\
\hline Golfo & 32 & 10 & 2,66 \\
\hline Terremoto & 31 & 16 & 1,61 \\
\hline Península & 28 & 6 & 2,89 \\
\hline Nevado & 24 & 1 & 4,17 \\
\hline Llanura & 23 & 0 & 3,74 \\
\hline Cabo & 19 & 7 & 2,63 \\
\hline Río & 16 & 4 & 2,94 \\
\hline Bahía & 15 & 3 & 3,00 \\
\hline Isla & 15 & 4 & 3,20 \\
\hline Colina & 15 & 0 & 4,13 \\
\hline Maremoto & 12 & 1 & 3,17 \\
\hline Temblor & 12 & 5 & 2,67 \\
\hline Cañón & 10 & 1 & 3,60 \\
\hline Derrumbe & 10 & 4 & 2,00 \\
\hline
\end{tabular}

\begin{tabular}{|l|c|c|c|}
\hline \multicolumn{5}{|c|}{ 29. Un deporte } \\
\hline \multicolumn{1}{|c|}{ Palabra } & Frecuencia & Primer Lugar & Rango \\
\hline Fútbol & 193 & 113 & 1,89 \\
\hline Tenis & 124 & 22 & 3,35 \\
\hline Natación & 120 & 15 & 3,87 \\
\hline Voleibol & 116 & 5 & 3,81 \\
\hline Baloncesto & 87 & 13 & 2,98 \\
\hline Basketball & 72 & 8 & 3,28 \\
\hline Atletismo & 61 & 3 & 5,20 \\
\hline Gimnasia & 53 & 3 & 4,98 \\
\hline Ciclismo & 44 & 2 & 4,36 \\
\hline Patinaje & 43 & 2 & 4,63 \\
\hline \multicolumn{4}{|c|}{} \\
\end{tabular}

\begin{tabular}{|c|c|c|c|}
\hline \multicolumn{4}{|c|}{ 30. Un fenómeno climático } \\
\hline Palabra & Frecuencia & Primer Lugar & Rango \\
\hline Huracán & 117 & 54 & 2,10 \\
\hline Lluvia & 100 & 54 & 2,11 \\
\hline Tormenta & 83 & 14 & 2,84 \\
\hline Tornado & 76 & 20 & 2,66 \\
\hline Sequía & 34 & 1 & 3,82 \\
\hline Maremoto & 29 & 2 & 3,52 \\
\hline Inundación & 25 & 2 & 3,52 \\
\hline Nieve & 25 & 2 & 3,00 \\
\hline Tsunami & 25 & 3 & 3,56 \\
\hline Terremoto & 23 & 4 & 3,22 \\
\hline $\begin{array}{l}\text { Fenómeno del } \\
\text { niño }\end{array}$ & 22 & 13 & 1,86 \\
\hline Granizo & 20 & 0 & 3,75 \\
\hline $\begin{array}{l}\text { Calentamiento } \\
\text { global }\end{array}$ & 18 & 6 & 2,72 \\
\hline Calor & 17 & 1 & 4,00 \\
\hline Ciclón & 17 & 2 & 3,24 \\
\hline Sol & 15 & 0 & 3,73 \\
\hline Nevada & 13 & 0 & 4,31 \\
\hline Frío & 12 & 1 & 3,50 \\
\hline Tifón & 12 & 2 & 3,25 \\
\hline Viento & 11 & 2 & 3,09 \\
\hline Invierno & 10 & 6 & 1,80 \\
\hline La niña & 10 & 3 & 2,40 \\
\hline Temblor & 10 & 0 & 4,30 \\
\hline Verano & 10 & 2 & 2,30 \\
\hline
\end{tabular}




\begin{tabular}{|c|c|c|c|}
\hline \multicolumn{4}{|c|}{ 31. Una prenda } \\
\hline Palabra & Frecuencia & Primer Lugar & Rango \\
\hline Pantalón & 184 & 38 & 2,77 \\
\hline Medias & 170 & 5 & 5,16 \\
\hline Camisa & 156 & 26 & 3,86 \\
\hline Chaqueta & 142 & 25 & 4,51 \\
\hline Camiseta & 111 & 10 & 4,64 \\
\hline Zapatos & 111 & 6 & 5,11 \\
\hline Saco & 101 & 36 & 3,80 \\
\hline Falda & 82 & 17 & 3,88 \\
\hline Blusa & 66 & 9 & 4,36 \\
\hline Brassiere & 57 & 4 & 5,84 \\
\hline Buso & 49 & 2 & 5,59 \\
\hline Bufanda & 46 & 0 & 7,22 \\
\hline Gorro & 43 & 2 & 6,44 \\
\hline Boxers & 38 & 2 & 5,26 \\
\hline Jean & 34 & 8 & 2,97 \\
\hline Pantaloneta & 34 & 0 & 6,85 \\
\hline Corbata & 28 & 2 & 6,11 \\
\hline Chaleco & 22 & 1 & 6,55 \\
\hline Guantes & 22 & 0 & 8,14 \\
\hline Calzoncillos & 20 & 1 & 5,70 \\
\hline Tenis & 20 & 1 & 5,10 \\
\hline Ropa interior & 18 & 0 & 6,89 \\
\hline Sombrero & 18 & 0 & 7,33 \\
\hline Vestido & 18 & 5 & 5,28 \\
\hline Panty & 17 & 1 & 5,29 \\
\hline Abrigo & 15 & 1 & 7,73 \\
\hline Tanga & 14 & 3 & 5,21 \\
\hline Botas & 12 & 0 & 7,33 \\
\hline Interiores & 12 & 0 & 5,83 \\
\hline Cinturón & 11 & 0 & 7,45 \\
\hline Cucos & 10 & 1 & 5,50 \\
\hline
\end{tabular}

\begin{tabular}{|l|c|c|c|}
\hline Recepción & 55 & 6 & 3,40 \\
\hline Sótano & 51 & 16 & 3,08 \\
\hline Oficinas & 46 & 5 & 3,72 \\
\hline Parqueadero & 39 & 3 & 4,05 \\
\hline Entrada & 33 & 11 & 3,06 \\
\hline Portería & 25 & 3 & 3,36 \\
\hline Cuarto & 23 & 2 & 4,78 \\
\hline Techo & 23 & 3 & 4,74 \\
\hline Apartamentos & 22 & 2 & 4,41 \\
\hline Azotea & 21 & 4 & 4,14 \\
\hline Balcón & 19 & 1 & 4,21 \\
\hline Pared & 18 & 2 & 4,83 \\
\hline Salón & 18 & 1 & 4,22 \\
\hline Pasillo & 17 & 3 & 3,76 \\
\hline Salida & 14 & 1 & 4,93 \\
\hline Garaje & 13 & 2 & 3,92 \\
\hline Hall & 13 & 2 & 3,46 \\
\hline Columna & 11 & 4 & 2,64 \\
\hline Sala & 10 & 0 & 4,30 \\
\hline
\end{tabular}

\begin{tabular}{|l|c|c|c|}
\hline \multicolumn{4}{|c|}{ 33. Un elemento químico } \\
\hline \multicolumn{1}{|c|}{ Palabra } & Frecuencia & Primer Lugar & Rango \\
\hline Oxígeno & 103 & 9 & 3,87 \\
\hline Hidrógeno & 95 & 24 & 3,29 \\
\hline Sodio & 56 & 15 & 3,38 \\
\hline Carbono & 55 & 6 & 4,42 \\
\hline Potasio & 53 & 4 & 4,06 \\
\hline Hierro & 51 & 13 & 3,71 \\
\hline Azufre & 47 & 16 & 3,19 \\
\hline Nitrógeno & 44 & 9 & 3,66 \\
\hline Calcio & 39 & 5 & 4,41 \\
\hline Oro & 39 & 6 & 4,46 \\
\hline Helio & 35 & 10 & 3,06 \\
\hline Plata & 35 & 3 & 4,80 \\
\hline Cloro & 31 & 0 & 4,61 \\
\hline Zinc & 30 & 2 & 4,33 \\
\hline Magnesio & 29 & 2 & 5,59 \\
\hline Aluminio & 28 & 3 & 4,29 \\
\hline Litio & 28 & 2 & 3,86 \\
\hline Fósforo & 26 & 5 & 4,69 \\
\hline Cobre & 19 & 4 & 4,70 \\
\hline Boro & 18 & 4 & 5,21 \\
\hline Mercurio & & 0 & 4,68 \\
\hline Ácido & 8 & 2,33 \\
\hline & & & Continúa \\
\hline
\end{tabular}




\begin{tabular}{|l|l|l|l|}
\hline Neón & 18 & 1 & 5,44 \\
\hline Berilio & 15 & 0 & 5,67 \\
\hline Níquel & 15 & 2 & 3,87 \\
\hline Agua & 14 & 7 & 2,21 \\
\hline Uranio & 14 & 3 & 4,14 \\
\hline Plomo & 13 & 5 & 3,23 \\
\hline Estaño & 12 & 1 & 5,00 \\
\hline H2o & 12 & 5 & 2,50 \\
\hline Yodo & 11 & 0 & 6,36 \\
\hline Bromo & 10 & 1 & 4,60 \\
\hline
\end{tabular}

\begin{tabular}{|l|c|c|c|}
\hline \multicolumn{5}{|c|}{ 35. Una moneda } \\
\hline \multicolumn{1}{|c|}{ Palabra } & Frecuencia & Primer Lugar & Rango \\
\hline Peso & 195 & 99 & 2,05 \\
\hline Dólar & 176 & 19 & 2,77 \\
\hline Euro & 164 & 47 & 2,85 \\
\hline Bolívar & 92 & 3 & 4,36 \\
\hline Yen & 92 & 11 & 3,95 \\
\hline Libra & 87 & 3 & 4,10 \\
\hline Sol & 44 & 4 & 4,39 \\
\hline Centavo & 35 & 4 & 3,60 \\
\hline Franco & 30 & 2 & 4,50 \\
\hline Peseta & 28 & 0 & 4,50 \\
\hline Yuan & 18 & 1 & 3,94 \\
\hline Lira & 14 & 1 & 5,07 \\
\hline
\end{tabular}

34. Un instrumento

\begin{tabular}{|c|c|c|c|}
\hline Palabra & Frecuencia & Primer Lugar & Rango \\
\hline Guitarra & 203 & 100 & 1,94 \\
\hline Piano & 146 & 19 & 3,84 \\
\hline Batería & 135 & 12 & 4,13 \\
\hline Flauta & 135 & 25 & 4,20 \\
\hline Violín & 128 & 14 & 4,70 \\
\hline Tambor & 97 & 2 & 5,04 \\
\hline Bajo & 82 & 6 & 4,17 \\
\hline Trompeta & 77 & 6 & 5,53 \\
\hline Saxofón & 72 & 10 & 5,07 \\
\hline Maracas & 56 & 0 & 5,71 \\
\hline Acordeón & 52 & 1 & 4,88 \\
\hline Violonchelo & 36 & 0 & 5,94 \\
\hline Clarinete & 34 & 3 & 5,88 \\
\hline Arpa & 33 & 3 & 5,24 \\
\hline Trombón & 28 & 0 & 6,25 \\
\hline Organeta & 27 & 0 & 5,96 \\
\hline Guacharaca & 20 & 0 & 5,20 \\
\hline Pandereta & 20 & 1 & 5,55 \\
\hline Timbal & 18 & 1 & 6,56 \\
\hline Gaita & 17 & 0 & 5,47 \\
\hline Órgano & 17 & 0 & 5,29 \\
\hline Contrabajo & 16 & 0 & 7,19 \\
\hline Platillo & 16 & 0 & 6,88 \\
\hline Tiple & 16 & 0 & 6,75 \\
\hline Viola & 16 & 0 & 7,38 \\
\hline Chelo & 14 & 1 & 6,57 \\
\hline Armónica & 13 & 1 & 5,15 \\
\hline Conga & 13 & 0 & 5,85 \\
\hline Lira & 13 & 0 & 6,46 \\
\hline Cuatro & 11 & 0 & 5,64 \\
\hline
\end{tabular}

\begin{tabular}{|l|c|c|c|}
\hline \multicolumn{5}{|c|}{ 36. Un tipo de música } \\
\hline \multicolumn{1}{|c|}{ Palabra } & Frecuencia & Primer Lugar & Rango \\
\hline Rock & 178 & 106 & 2,04 \\
\hline Salsa & 133 & 10 & 4,38 \\
\hline Vallenato & 125 & 9 & 4,39 \\
\hline Pop & 104 & 13 & 3,56 \\
\hline Merengue & 100 & 0 & 5,52 \\
\hline Metal & 68 & 10 & 4,51 \\
\hline Reggae & 66 & 7 & 4,83 \\
\hline Reggaetón & 62 & 0 & 5,42 \\
\hline Clásica & 60 & 8 & 4,52 \\
\hline Jazz & 59 & 8 & 4,64 \\
\hline Electrónica & 40 & 4 & 5,25 \\
\hline Balada & 36 & 2 & 4,67 \\
\hline Hip hop & 34 & 3 & 5,53 \\
\hline Punk & 31 & 2 & 4,42 \\
\hline Ranchera & 25 & 1 & 5,88 \\
\hline Rap & 25 & 2 & 5,60 \\
\hline Blues & 25 & 0 & 5,44 \\
\hline Cumbia & 22 & 0 & 6,41 \\
\hline Romántica & 18 & 0 & 5,67 \\
\hline Tropipop & 17 & 0 & 5,76 \\
\hline Instrumental & 12 & 0 & 5,08 \\
\hline Tropical & 11 & 1 & 5,55 \\
\hline Bolero & 10 & 0 & 5,90 \\
\hline Popular & 10 & 0 & 6,60 \\
\hline
\end{tabular}




\begin{tabular}{|c|c|c|c|}
\hline \multicolumn{4}{|c|}{ 37. Un ave } \\
\hline Palabra & Frecuencia & Primer Lugar & Rango \\
\hline Paloma & 135 & 43 & 2,94 \\
\hline Águila & 132 & 31 & 2,86 \\
\hline Cóndor & 65 & 11 & 3,77 \\
\hline Gallina & 65 & 15 & 3,31 \\
\hline Avestruz & 60 & 14 & 3,35 \\
\hline Loro & 58 & 8 & 4,36 \\
\hline Canario & 54 & 2 & 4,31 \\
\hline Pájaro & 47 & 21 & 2,28 \\
\hline Colibrí & 45 & 8 & 3,56 \\
\hline Chulo & 44 & 1 & 4,68 \\
\hline Pato & 44 & 3 & 4,55 \\
\hline Perico & 33 & 0 & 5,24 \\
\hline Pollo & 31 & 9 & 3,29 \\
\hline Gorrión & 30 & 5 & 3,97 \\
\hline Halcón & 28 & 1 & 4,07 \\
\hline Gaviota & 25 & 1 & 4,60 \\
\hline Golondrina & 24 & 4 & 4,08 \\
\hline Garza & 21 & 1 & 4,38 \\
\hline Cuervo & 20 & 3 & 3,90 \\
\hline Ganso & 20 & 0 & 5,20 \\
\hline Búho & 18 & 0 & 5,00 \\
\hline Pelícano & 17 & 1 & 4,82 \\
\hline Codorniz & 16 & 2 & 4,81 \\
\hline Mirla & 14 & 1 & 5,86 \\
\hline Azulejo & 14 & 1 & 5,07 \\
\hline Guacamaya & 14 & 1 & 4,64 \\
\hline Gavilán & 13 & 0 & 4,77 \\
\hline Copetón & 12 & 0 & 4,83 \\
\hline Pingüino & 12 & 3 & 4,08 \\
\hline Flamenco & 11 & 0 & 5,91 \\
\hline Cigüeña & 10 & 1 & 4,00 \\
\hline Flamingo & 10 & 0 & 5,60 \\
\hline
\end{tabular}

\begin{tabular}{|l|c|c|c|}
\hline Chocolate & 39 & 1 & 5,10 \\
\hline Tinto & 37 & 1 & 4,59 \\
\hline Yogurt & 34 & 0 & 5,32 \\
\hline Refresco & 29 & 0 & 4,45 \\
\hline Malteada & 24 & 0 & 4,17 \\
\hline Aromática & 19 & 0 & 6,26 \\
\hline Coca cola & 19 & 13 & 1,89 \\
\hline Aguadepanela & 14 & 0 & 5,14 \\
\hline Bebida energizante & 13 & 0 & 4,85 \\
\hline Kumis & 13 & 0 & 6,08 \\
\hline Soda & 13 & 0 & 4,23 \\
\hline Red Bull & 10 & 1 & 3,60 \\
\hline
\end{tabular}

\begin{tabular}{|c|c|c|c|}
\hline \multicolumn{4}{|c|}{ 39. Un medio de transporte } \\
\hline Palabra & Frecuencia & Primer Lugar & Rango \\
\hline Carro & 159 & 126 & 1,43 \\
\hline Bus & 90 & 6 & 3,69 \\
\hline Moto & 87 & 8 & 3,56 \\
\hline Camión & 83 & 11 & 3,49 \\
\hline Bicicleta & 75 & 3 & 4,03 \\
\hline Camioneta & 68 & 3 & 3,74 \\
\hline Avión & 64 & 4 & 3,92 \\
\hline Tren & 48 & 2 & 4,35 \\
\hline Tractomula & 34 & 0 & 4,50 \\
\hline Taxi & 33 & 3 & 4,03 \\
\hline Mazda & 31 & 12 & 2,97 \\
\hline Barco & 29 & 1 & 5,52 \\
\hline Transmilenio & 24 & 1 & 4,33 \\
\hline Automóvil & 20 & 8 & 2,60 \\
\hline Buseta & 20 & 0 & 4,75 \\
\hline Metro & 20 & 0 & 6,00 \\
\hline Volqueta & 19 & 0 & 4,68 \\
\hline Patines & 16 & 0 & 5,56 \\
\hline Renault & 16 & 1 & 4,31 \\
\hline Chevrolet & 15 & 2 & 3,47 \\
\hline Mercedes Benz & 14 & 1 & 3,71 \\
\hline Patineta & 14 & 0 & 5,71 \\
\hline Tractor & 14 & 1 & 4,36 \\
\hline BMW & 13 & 5 & 2,77 \\
\hline Cicla & 12 & 1 & 3,50 \\
\hline Colectivo & 11 & 0 & 5,36 \\
\hline Triciclo & 11 & 0 & 6,18 \\
\hline Helicóptero & 10 & 0 & 5,40 \\
\hline Toyota & 10 & 1 & 3,80 \\
\hline
\end{tabular}

\begin{tabular}{|l|c|c|c|}
\hline \multicolumn{4}{|c|}{ 38. Una bebida no alcohólica } \\
\hline \multicolumn{1}{|c|}{ Palabra } & Frecuencia & Primer Lugar & Rango \\
\hline Jugo & 188 & 40 & 2,57 \\
\hline Agua & 183 & 34 & 2,86 \\
\hline Gaseosa & 175 & 96 & 1,97 \\
\hline Café & 77 & 12 & 4,03 \\
\hline Leche & 53 & 2 & 4,68 \\
\hline Té & 52 & 4 & 4,46 \\
\hline Limonada & 45 & 2 & 3,91 \\
\hline
\end{tabular}




\begin{tabular}{|l|c|c|c|}
\hline \multicolumn{5}{|c|}{ 40. Una ciencia } \\
\hline \multicolumn{1}{|c|}{ Palabra } & Frecuencia & Primer Lugar & Rango \\
\hline Química & 98 & 14 & 3,24 \\
\hline Matemáticas & 94 & 26 & 2,72 \\
\hline Física & 87 & 12 & 3,18 \\
\hline Biología & 86 & 28 & 2,53 \\
\hline Lingüística & 71 & 25 & 3,04 \\
\hline Filosofía & 54 & 13 & 3,04 \\
\hline Ciencias sociales & 51 & 13 & 2,45 \\
\hline Medicina & 48 & 12 & 3,06 \\
\hline Psicología & 41 & 10 & 3,17 \\
\hline Antropología & 37 & 4 & 3,57 \\
\hline Ciencias naturales & 27 & 9 & 2,26 \\
\hline Sociología & 22 & 5 & 3,36 \\
\hline Geografía & 20 & 1 & 4,00 \\
\hline Pedagogía & 18 & 6 & 3,06 \\
\hline Historia & 16 & 3 & 3,81 \\
\hline Políica & 14 & 5 & 2,50 \\
\hline Astronomía & 13 & 1 & 3,38 \\
\hline Filología & 11 & 1 & 3,91 \\
\hline Educación & 10 & 0 & 3,50 \\
\hline
\end{tabular}

\begin{tabular}{|l|l|l|l|}
\hline Lego & 10 & 1 & 4,00 \\
\hline Patines & 10 & 0 & 3,90 \\
\hline Playstation & 10 & 2 & 3,20 \\
\hline
\end{tabular}

\begin{tabular}{|l|c|c|c|}
\hline \multicolumn{5}{|c|}{ 42. Un baile } \\
\hline \multicolumn{1}{|c|}{ Palabra } & Frecuencia & Primer Lugar & Rango \\
\hline Cumbia & 117 & 35 & 2,62 \\
\hline Salsa & 94 & 35 & 2,56 \\
\hline Tango & 82 & 17 & 3,21 \\
\hline Joropo & 73 & 25 & 2,63 \\
\hline Mapalé & 56 & 9 & 3,18 \\
\hline San juanero & 49 & 13 & 2,65 \\
\hline Merengue & 48 & 5 & 2,88 \\
\hline Bambuco & 23 & 6 & 3,04 \\
\hline Reggaetón & 23 & 3 & 3,74 \\
\hline Vals & 23 & 7 & 3,26 \\
\hline Flamenco & 20 & 6 & 3,10 \\
\hline Currulao & 18 & 2 & 3,50 \\
\hline Samba & 18 & 4 & 2,67 \\
\hline Porro & 16 & 1 & 3,38 \\
\hline Pasillo & 15 & 1 & 4,07 \\
\hline Árabe & 13 & 1 & 3,62 \\
\hline Torbellino & 13 & 2 & 3,15 \\
\hline Vallenato & 13 & 1 & 3,62 \\
\hline Ballet & 12 & 0 & 4,00 \\
\hline Guabina & 11 & 0 & 4,27 \\
\hline Polka & 11 & 1 & 3,64 \\
\hline
\end{tabular}

\begin{tabular}{|l|c|c|c|}
\hline \multicolumn{5}{|c}{ 41. Un juguete } \\
\hline \multicolumn{1}{|c|}{ Palabra } & Frecuencia & Primer Lugar & Rango \\
\hline Carro & 182 & 88 & 1,82 \\
\hline Muñeca & 132 & 44 & 2,21 \\
\hline Balón & 89 & 20 & 3,46 \\
\hline Barbie & 59 & 11 & 3,34 \\
\hline Muñeco & 51 & 11 & 2,67 \\
\hline Peluche & 44 & 2 & 3,86 \\
\hline Pelota & 41 & 6 & 3,80 \\
\hline Oso & 26 & 7 & 3,19 \\
\hline Armatodo & 21 & 2 & 4,05 \\
\hline Rompecabezas & 19 & 1 & 4,89 \\
\hline Xbox & 16 & 2 & 4,06 \\
\hline Avión & 13 & 0 & 3,69 \\
\hline Trompo & 13 & 1 & 4,38 \\
\hline Bicicleta & 12 & 0 & 4,17 \\
\hline Lazo & 12 & 1 & 4,00 \\
\hline Sonajero & 12 & 1 & 4,17 \\
\hline Yoyo & 12 & 0 & 4,42 \\
\hline Tren & 11 & 0 & 3,18 \\
\hline Cocinita & 10 & 0 & 4,20 \\
\hline & & & Continúa \\
\hline & & & \\
\hline
\end{tabular}

\begin{tabular}{|l|c|c|c|}
\hline \multicolumn{5}{|c|}{ 43. Una verdura } \\
\hline \multicolumn{1}{|c|}{ Palabra } & Frecuencia & Primer Lugar & Rango \\
\hline Lechuga & 116 & 29 & 3,00 \\
\hline Zanahoria & 114 & 26 & 3,10 \\
\hline Habichuela & 109 & 47 & 2,33 \\
\hline Arveja & 96 & 23 & 2,67 \\
\hline Espinaca & 90 & 18 & 3,52 \\
\hline Tomate & 86 & 20 & 3,15 \\
\hline Cebolla & 64 & 3 & 4,34 \\
\hline Coliflor & 58 & 6 & 3,91 \\
\hline Pepino & 52 & 7 & 3,98 \\
\hline Brócoli & 47 & 6 & 3,47 \\
\hline Repollo & 43 & 2 & 4,14 \\
\hline Acelga & 30 & 3 & 4,07 \\
\hline Remolacha & 30 & 3 & 4,07 \\
\hline
\end{tabular}




\begin{tabular}{|l|l|l|l|}
\hline Apio & 29 & 4 & 4,28 \\
\hline Pimentón & 22 & 1 & 5,14 \\
\hline Calabaza & 16 & 1 & 4,31 \\
\hline Ahuyama & 13 & 0 & 4,62 \\
\hline Rábano & 11 & 0 & 5,09 \\
\hline
\end{tabular}

\begin{tabular}{|l|c|c|c|}
\hline \multicolumn{5}{|c|}{ 45. Un insecto } \\
\hline \multicolumn{1}{|c|}{ Palabra } & Frecuencia & Primer Lugar & Rango \\
\hline Mosca & 139 & 61 & 2,37 \\
\hline Zancudo & 123 & 21 & 3,00 \\
\hline Cucaracha & 104 & 20 & 3,04 \\
\hline Araña & 85 & 21 & 3,13 \\
\hline Abeja & 67 & 7 & 3,87 \\
\hline Hormiga & 67 & 7 & 4,13 \\
\hline Mariposa & 53 & 8 & 3,96 \\
\hline Pulga & 47 & 8 & 3,26 \\
\hline Cucarrón & 42 & 4 & 3,86 \\
\hline Gusano & 42 & 3 & 4,60 \\
\hline Grillo & 37 & 11 & 2,76 \\
\hline Mariquita & 33 & 5 & 3,79 \\
\hline Mosquito & 33 & 9 & 3,36 \\
\hline Mosco & 27 & 9 & 2,52 \\
\hline Avispa & 24 & 0 & 4,46 \\
\hline Ciempiés & 24 & 0 & 4,79 \\
\hline Saltamontes & 23 & 0 & 4,74 \\
\hline Escarabajo & 22 & 4 & 4,36 \\
\hline Libélula & 22 & 4 & 3,68 \\
\hline Polilla & 19 & 1 & 5,42 \\
\hline Mantis & 17 & 5 & 3,29 \\
\hline Piojo & 16 & 0 & 5,19 \\
\hline Lombriz & 15 & 2 & 4,27 \\
\hline Garrapata & 13 & 0 & 5,00 \\
\hline
\end{tabular}

\begin{tabular}{|l|c|c|c|}
\hline \multicolumn{4}{|c|}{ 44. Un tipo de calzado } \\
\hline \multicolumn{1}{|c|}{ Palabra } & Frecuencia & Primer Lugar & Rango \\
\hline Tenis & 184 & 68 & 2,17 \\
\hline Botas & 149 & 37 & 2,79 \\
\hline Sandalias & 118 & 12 & 3,42 \\
\hline Zapatos & 102 & 38 & 2,31 \\
\hline Tacones & 90 & 16 & 3,37 \\
\hline Zapatillas & 58 & 9 & 3,62 \\
\hline Chanclas & 57 & 2 & 3,96 \\
\hline Valetas & 41 & 2 & 3,88 \\
\hline Chancletas & 39 & 2 & 4,31 \\
\hline Pantuflas & 35 & 0 & 4,91 \\
\hline Mocasín & 28 & 4 & 3,64 \\
\hline Alpargatas & 22 & 0 & 5,00 \\
\hline Babuchas & 18 & 0 & 4,89 \\
\hline Botín & 16 & 0 & 4,75 \\
\hline Suecos & 15 & 2 & 3,87 \\
\hline Guayos & 11 & 1 & 4,18 \\
\hline Formales & 10 & 0 & 4,30 \\
\hline
\end{tabular}




\section{Bibliografía}

Battig, W. F. y Montague, W. E. (1969). 'Category norms of verbal items in 56 categories: A replication and extension of the Connecticut category norms'. Journal of Experimental Psychology, 80, 1-46.

Dubois, D. y Poitou, J. (2002). 'Normes catégorielles pour 22 catégories sémantiques du français et 10 catégories sémantiques de l'allemand'. Cahiers $d u$ LCPE , 5, 35-118.

Goikoetxea, E. (2000). 'Frecuencia de producción de las respuestas a 52 categorías verbales en niños de primaria’. Psicológica, 21, 61-89.

Mateus, G. y Santiago, A. (2006). 'Disponibilidad léxica en estudiantes bogotanos'. Folios, 24, 3-26. Bogotá: Universidad Pedagógica Nacional.
Pascual, J. L. y Musitu, G. O. (1980). Normas categoriales. Psicológica, 1, 157-174.

Ruts, W., De Deyne, S., Ameel, E., Vanpaemel, W., Verbeemen, T. y Storms, G. (2004). 'Dutch norm data for 13 semantic categories and 338 exemplars'. Behavior Research Methods, Instruments, y Computers. 36 (3), 506-515.

Yoon, C., Feinberg, F., Hall, A., Hedden, T., Chen, H., Jing, Q., Cui, Y., y Park, D. (2004). 'Category Norms as a Function of Culture and Age: Comparisons of Item Responses to 105 Categories by American and Chinese Adults. Psychology and Aging'. Vol. 19, $\mathrm{n}^{\circ}$. 3, 379-393. 